\title{
TSUNAMI AFFECTED FARMLAND EXTRACTION USING MORPHOLOGICAL PROFILES (MPS) METHOD BY SATELLITE IMAGES INCLUDING SAR AND VISIBLE- NEAR-INFRARED BAND DATA
}

\author{
Y.Yamada ${ }^{a}$ \\ a National Agriculture and Food Research Organization (NARO) 2-1-6 Kannondai, Tsukuba, Ibaraki 305-8609, Japan - \\ yamaday@affrc.go.jp
}

THEME: Natural Disasters Monitoring, Warning and Response

KEY WORDS: Morphological Profiles(MPs), Tsunami, SAR, farmland

\begin{abstract}
:
The agricultural fields along the coast were submerged under the sea water after the 2011 off the Pacific Coast of Tohoku Japan Tsunami. The conventional method of detecting Tsunami reached area by SAR satellite data is to compare the data obtained between previous to and after the Tsunami. However such kind of SAR data should be prepared prior to the natural disaster, but in many disaster cases, people have often encountered difficulties in finding such kind of data observed in advance in some regions. Therefore it is desirable to find a way to detect the flood suffering farmlands caused by a Tsunami, using only data observed after the disaster event. The morphological profiles (MPs) method are tested using ALOS/PALSAR and AVNIR-2 data. This MPs method is proposed as the tool for extracting information about the size, shape and the orientation of structures in single-band remote sensing images and has been improved to establish the extended morphological profiles(EMP) dealing with full-spectral information in the multi-/hyper-spectral data (Benediktsson, J.A. et al.,2003,2005). The author's work is intended to apply this MPs method to combined single polarization SAR data and visual and near-infrared bands data. The results approximately coincide with the farmland regions actually reached by the Tsunami. This MPs method requires only data once obtained soon after a disaster light computer resources and very short turnaround time. It should be suitable for the detection of Tsunami reached areas or tidal wave reached areas, caused by a Typhoon for example, using satellite data only once obtained after a disaster.
\end{abstract}

\section{INTRODUCTION}

\subsection{Morphological Profiles}

The mathematical morphology filtering method is an alternative measure to the conventional image processing. It was first introduced in 1964 by J.Serra and G. Matheron in France as a method for oreassaying(Plaza, 2005, Soille,2003). They are making efforts to replace the conventional image processing method with mathematical morphology filtering.(Takagi,2004) This mathematical morphology method is suitable for computer operational measurement, because its operation is combined with simple procedures using localized information.(Takagi,2004) The extension of mathematical morphology to hyperspectral imagery for spatial and spectral data processing was done by (Soille, P.,2003), (Pesaresi,M. et al.,2001)

The mathematical morphology profiles(MPs) method is proposed as the tool for extracting information about the size, shape and the orientation of structures in single-band remote sensing images and has been improved to establish the extended morphological profiles(EMP) dealing with full spectral information in the multi-/hyper-spectral data (Benediktsson, J.A. et al.,2003,2005). To calculate EMP, the primary principal components, $\mathrm{PCs}$, are derived from principal component analysis(PCA) to the hyperspectral data. These MPs are kind of tools to combine spectral and spatial information for classification of multi-/hyper-spectral data.
This morphological profiles method has been extended to include use for classifying both multispectral data and polarimetric SAR data (Marpu,P.R., et al.,2011).

\subsection{Off the Pacific Coast of Tohoku Japan Tsunami}

A great earthquake and resulting huge tsunami occurred on March 11th, 2011 over wide areas of north-eastern Japan. Agricultural fields along the coast were submerged under the seawater brought by the Tsunami wave for long periods. Repeated Tsunami waves left demolition debris and rubbish or house hold items on the farmland. The most of farmlands in this area along Pacific Ocean are paddy fields.

\subsection{Previous studies for the 2011 Tsunami}

Tsunami damage investigation of built-up areas using spaceborne full polarimetric SAR images was successfully done by S-Wei Chen and M. Sato(2013). As for urban areas, 2011 Tsunami damages are tried using both spaceborne and airborne L-band full-polarimetric SAR data.(M. Watanabe et al., 2012) But these analysis are not for farmland areas. The COSMO-SkyMed SAR analysis for the 2011 Tsunami was performed by M. Chini et al. (2012) Their report showed that it was possible to detect not only the flooded areas, but also receding of the floodwater and the moving of the debris using X-band SAR data. 


\subsection{Research area}

The research area is the Southern coast of Miyagi prefecture off the Pacific coast. The epicenter of the earthquake is shown surrounding the Japanese Main Island in Figure1. as a circle with slant lines. The rectangle mark, "A", means the bounds of epicenters of aftershocks. The agricultural fields along the coast were submerged by seawater caused by the Tsunami because of the destruction of drainage pumps for some periods. There were a lot of debris, rubble and thick soil on the ground carried by the Tsunami. These obstacles have to be removed first. As the farmland along the coast is under a poor drainage condition, pumping water is always necessary.(The Japanese Society of Rural Development Engineers, 2012) The soil in such farmland suffered from the salt in sea water. The soil salinity hinders the crop growth, hence the detection of Tsunami inundated farmland is important for agriculture.

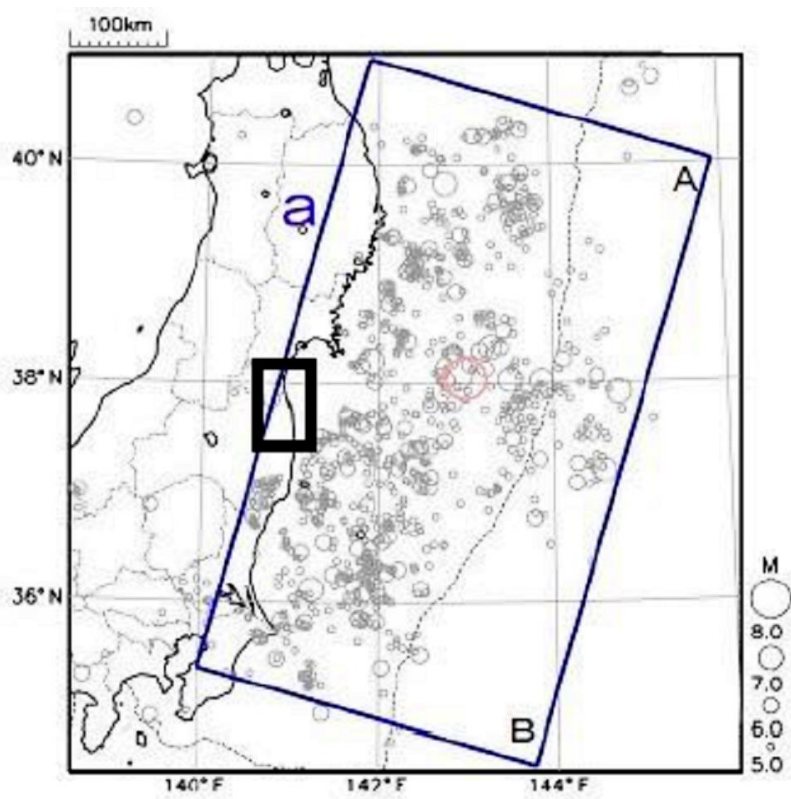

Figure 1. the epicenters distributed off the Pacific coast (Japan Meteorological Agency,2014) and the research area (a central rectangle) shown in the eastern part of the Japanese Main Island

\section{METHODS}

\section{1 mathematical morphology}

Mathematical morphology operators consist of erosion, dilation and their combinations, opening operation and closing operation. (Bioucas-Dias, 2012,

2013)(Doughery,1992)(Frank,1996)(Kobatake,1996)(Takagi,2 004)(Russ,2011) Basically dilation procedure adds a layer around the peripheral pixels of all features in the image. And erosion procedure adds or rips off some pixels from the figure. The opening operation is consecutive erosion and dilation. It can be used in some cases to separate touching features. The closing operation is consecutive dilation and erosion. It closes breaks in features. The result is different depending upon the order of application of the two procedures. SAR signal intensity for each pixel includes some interactive information between microwave and terrain feature on the ground.(Iisaka,1989, 1998, 2000,1992, 1994, 1994, 1995) Mathematical morphology processing is one method for detecting such spatial information. (Yamada, 2002, 2001, 2003, 2008, 2007, 2011, 2012, 2012, 2013)(Pijush, 2008)

* Morphological operators (Kobatake,1996)

$\mathrm{A} \boldsymbol{\Delta} \mathrm{B}=\{\mathrm{c} \in \mathrm{EN} \mid \mathrm{c}=\mathrm{a}+\mathrm{b}, \mathrm{a} \forall \in \mathrm{A}, \mathrm{b} \forall \in \mathrm{B}\}$; dilation operation

$\mathrm{A} \nabla \mathrm{B}=\{\mathrm{x} \in \mathrm{EN} \mid \mathrm{x}+\mathrm{b} \in \mathrm{A}, \mathrm{b} \forall \in \mathrm{B}\}$; erosion operation (2)

$\mathrm{A} \circ \mathrm{B}=(\mathrm{A} \nabla \mathrm{B}) \boldsymbol{\Delta} \mathrm{B} ;$ opening operation

(3)

$\mathrm{A} \bullet \mathrm{B}=[\mathrm{A} \boldsymbol{\Lambda}(\mathrm{B})] \nabla(\mathrm{B})$; closing operation

(4)

\subsection{The morphological profiles(MPs)}

As for the morphological profiles (MPs), the mathematical morphology opening, filter size 9by9, and the closing procedure, filter size 9by9, was executed. The result does not clearly show the effect of detecting Tsunami damaged farmland. And for the AVNIR-2 multi-spectral data, first the principal components (PCs) are computed.

The principal component No.2, PC_2 is most likely to relate to the Tsunami damaged areas. Then the morphological opening, filter size 9 by 9 square, is done. The morphological closing, filter size 9 by 9 square, is done. Finally, the open-closing image is obtained by applying the closing procedure to the opening image. This image is the morphological profiles (MPs).

\section{DATA}

The following data uses in this analysis, ALOS/PALSAR data were used so that the JAXA's product level was 1.5; pixel spacing was 6.25 ; polarization is $\mathrm{HH}$; the observation date was March 13rd, 2011. ALOS/AVNIR-2 observed in March 14, 2011 are used for the analysis. The image threshold method is used to make a binary image from the original data. But as there are dark parts and bright regions in the same image, the fixed threshold-value often fails to obtain an appropriate binary image. A different threshold value is used for each pixel in the same image by the adaptive thresholding method.(Yamada,2012) Using the adaptive threshold method, filter size 15 by 15 pixels and the constant value 2200 were applied to the original PALSAR data, level $1.5 \mathrm{HH}$ data. The morphological opening filtering was applied to the image mentioned before, filter size 9 by 9 pixels.

This result is compared with the Restoration plan map for crop filed in Tsunami flooded areas by MAFF (Ministry of Agriculture, Forestry and Fisheries), GIA(Geospatial Information Authority )maximum inundated areas maps. Through the experiment, the window size of adaptive thresholding method is changed to 51 by 51 pixels according to the handbook of image analysis. (Takagi,M. et al.,2004)

\section{RESULTS}

The principal-component -2 of the set of AVNIR-2 and PALSAR HH data is good agreement with the Tsunami reached areas. Then the morphological opening, filter size 9by9 square, is done. Next, the morphological closing, filter size 9 by 9 square, is done. Finally, the open-closing image is obtained. (Figure 2) The red line in the Figure 2 is the official 
reported Tsunami maximum reached line. The region along Pacific Ocean inside the red line in the Figure 2 is apparently distinguished from the inland areas. The small and black rectangle in the upper side of the Figure 2 is the "Kasumime" helicopter base of the Japanese Air Self-Defense Force. The helicopter base is out of the Tsunami red line and was actually not submerged at the Tsunami event. But the most upper side of Figure2 is not clear outside or inside of the red line. This area is Sendai-Shiogama port and there are many port facilities, buildings.

The MPs figure, Figure2, is in fair agreement with the Tsunami reached areas in farmland region.

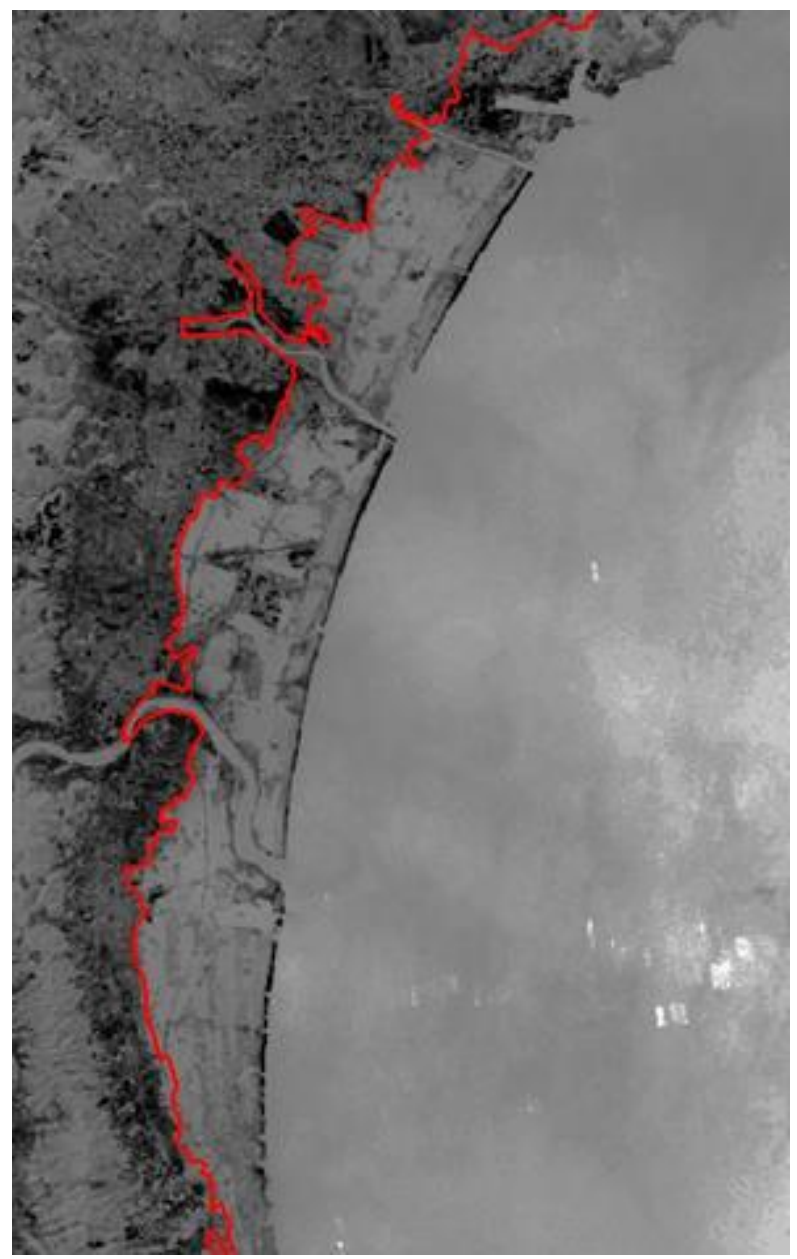

Figure2. Morphological profiles (MPs) 9by9 filter To confirm this procedure, using ALOS/PALSAR, HH, level 1.5 and AVNI-R-2, 4-band data, choosing principal component 2 image and calculating opening and closing procedure in 9by9 square filter, this method was applied to another scene which is the neighbor on the South. (Figure 3) The most likely morphological filter size for MPs is, judging from testing various filter sizes, the 9 by 9 square filter, too. The result for the analysis of morphological profiles (MPs) can easily distinguish the Tsunami reached areas with the inland areas, which the blue line is the boundary. The Tsunami reached areas are rather smooth than the inland areas.

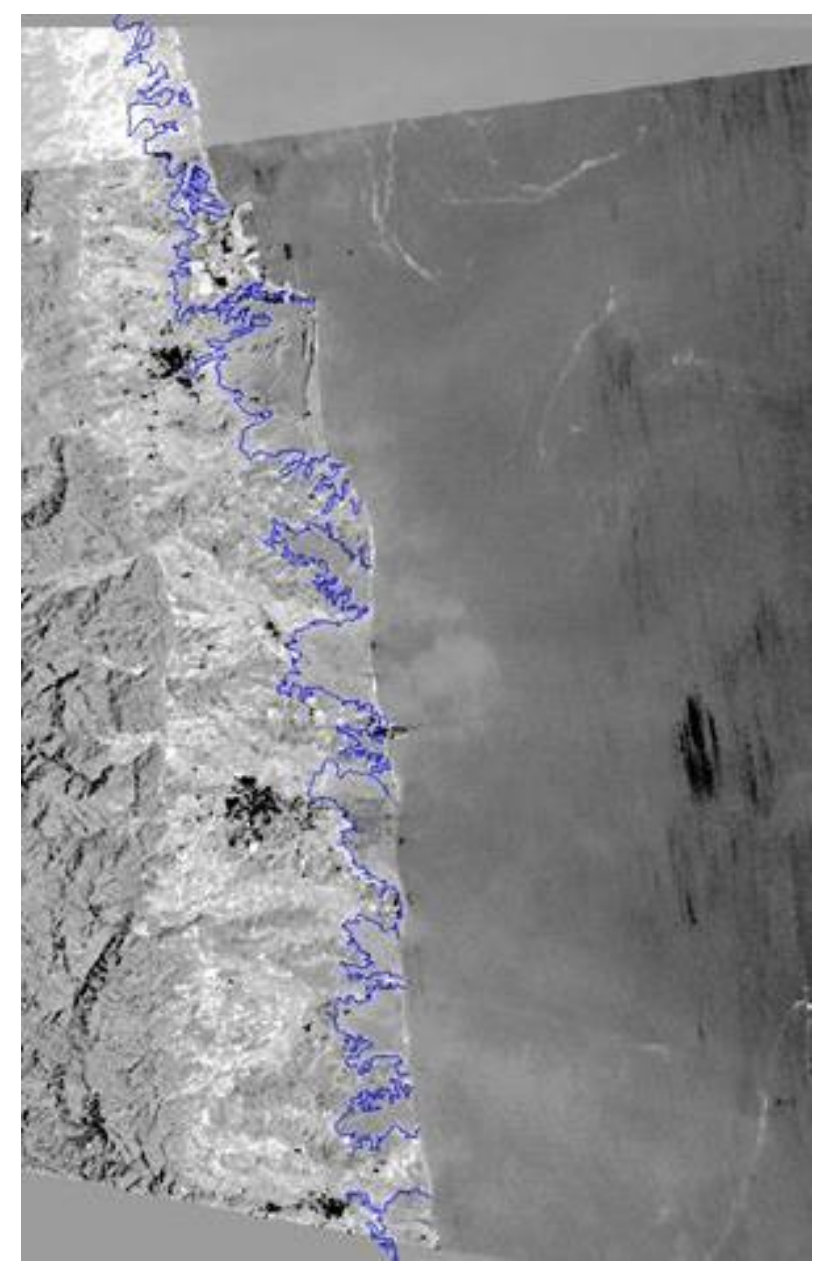

Figure3. Morphological profiles (MPs) 9by9 filter

\section{Conclusion}

In this paper, the morphological profiles method are tested as ways of detecting Tsunami affected farmland using both SAR and multispectral data. The result obtained from MPs using both L-band SAR HH polarization and multispectral data shows this approach has great potential as a way of making this detection. And the detected areas are in good agreement with the maximum Tsunami reached areas in paddy field and farmland. This MPs method requires only data obtained soon after a disaster, light computer resources and very short turnaround time. It should be suitable for the detection of Tsunami reached region or tidal wave reached areas, caused by a Typhoon for example. The ALOS-2 satellite takes over the ALOS satellite and it has the PALSAR-2 sensor, an Lband SAR. Therefore using the model based on MPs, damage by Tsunami or Typhoon could be estimated by both PALSAR2 and multi- or hyper-spectral sensor.

\section{REFERENCES}

Benediktsson,J.A.;Palmason,J.A.;Sveinsson,J.R. 2005. Classification of Hyperspectral Data From Urban Areas Based on Extended Morphological Profiles, IEEE Trans on Geoscience and Remote Sensing, 43,No. 3, 480-491 
Benediktsson, J.A.; Pesaresi, M.;Arnason, K.2003. Classication and Feature Extraction for Remote Sensing Images From Urban Areas Based on Morphological Transformations, IEEE Trans. On Geoscience and Remote Sensing, 41, No.9, 1940-1949

Bioucas-Dias,J. M.;Plaza A., Dobigeon,N.;Parente M., Du Q., Gader P.;Chanussot J.,2012 Hyperspectral Unmixing Overview: Geometrical, Statistical, and Sparse RegressionBased Approaches, IEEE J. of Selected Topics in Applied Earth Observation and Remote Sensing,No.2,pp.354-379

Bioucas-Dias,J. M.;Plaza A., 2013. Camps-Valls, G., Scheunders,P., Nasrabadi,N.M., Chanussot,J.,Hyperspectral Remote Sensing Data Analysis and Future Challenges, IEEE Geoscience and Remote Sensing Magazine, pp. 6-36

Chini,M., Pulvirenti,L. et al.,2012. Analysis and Interpretation of COSMO-SkyMed Observations of the 2011 Japan Tsunami, IEEE Geoscience and Remote Sensing Letters, vol.9,No.3,pp.467-471

Doughery,E.R., 1992. An Introduction to Morphological Image Processing, SPIE, Bellingham

Frank Y. Shih,2009. Image Processing and Mathematical Morphology Fundamentals and Applications, CRC Press, Boca Raton

Kobatake,1996. H. Morphology (in Japanese), Corona Publishing, pp.175-179, Tokyo

Iisaka,J.,1989. Structural Spatial Information Extraction from Remotely Sensed Data, Proceedings of IGARSS'89, Vancouver, Canada, pp.1224-1227

lisaka,J.,1998. A unified image computing method for spectral and spatial feature extraction from remotely sensed imagery, Proceedings of SPIE symposium on non-linear image processing IX, San Jose, U.S.A.,pp.232-239

Iisaka,J.;Sakurai-Amano, T.,2000. Image Analysis of Remote Sensing Data Integrating Spectral and Spatial Features of Objects, Proceedings of ACRS2000, 1-7

Iisaka,J.; Sakurai-Amano, T.,1992. Spatial Association for Radar Image Interpretation, Proceedings of IGARSS'92, Houston, pp.1200-1203

Iisaka,J.; Sakurai-Amano, T.,1994a. Terrain Feature Detection from SAR Data Based on Spatial Association of Objects, Proceedings of Tenth Thematic Conference on Geologic Remote Sensing, San Antonio, Texas, pp.9-12

Iisaka,J.; Sakurai-Amano,T., 1994b. Terrain Feature Recognition for SAR Imagery Employing Spatial Attributes of Targets, ISPRS Commission IV Symposium Spatial Information from Digital Photogrammetry and Computer Vision, Munich, (SPIE Archives) pp.399-408

Iisaka,J.; and Sakurai-Amano,T.,1995. A Shape-Based Object Recognition for Remote Sensing, Proceedings of IGARSS1995, Florence, pp.160-162
IshiiM., Okushima,L., Moriyama,H., Aizawa,M, 2012. Horticultural Structures Damaged Along the Coast Part of miyagi Prefecture by the 2011 off the pacific coast of Tohoku Earthquake(in Japanese), Technical Report of NIRE, No.213, pp. $89-103$

Marpu,P.R.; Chen,K.S., Chu, C.Y.; Benediktsson,J.A.,2011. SPECRAL-SPATIAL CLASSIFICATION OF POLARIMETRIC SAR DATA USING MORPHOLOGICAL PROFILES, Proc. of 3rd Asia-Pacific International SAR conference(APSAR2011), pp.1-3

Mura,M.D.; Benediktsson,J.A.; Waske,B., Bruzzone,L.,2010. Morphological Attribute Profiles for the Analysis of Very High Resolution Images, IEEE Trans. on Geoscience and Remote Sensing, Vol.48, No.10, pp.3747-3762

Palmason,J.A.; Benediktsson,J.A.; Arnason,K.,2003. Morphological Transformations and Feature Extraction for Urban Data with High Spectral and Spatial Resolution, Proc. of IGARSS2003, Toulouse, pp.470-472

Plaza,A.; Benediktsson,J.A.; Boardman,J.W.; Brazile,J.; Bruzzone,L.; Camps-Valls,G.; Chanusst,J.; Fauvel,M.; Gamba,P.; Gualtieri, A.; Marconcini,M.; Tilton,J.C.; Trianni,G.,2009. Recent advances in techniques for hyperspectral image processing, Remote Sensing of Environment, 113, S110-S122

Plaza,A.; Martinez,P., Plaza,J.; Perez,R.,2005. Dimensionary Reduction and Classification of Hyperspectral Image Data Using Sequences of Extended Morphological Transformations, IEEE Trans. on Geoscience and Remote Sensing, Vol.43, No.3, pp.466-479

Pesaresi,M.; Benediktsson,J. A.,2001. A New Approach for the Morphological Segmentation of High-Resolution Satellite Imagery, IEEE Tran. Geoscience and Remote Sensing, Vol.39, No.2,pp.309-320

Pijush K. Ghosh; Koichiro Deguchi, 2008.Mathematics of Shape Description A Morphological Approach to Image Processing and Computer Graphocs, John Wiley \& Sons, Singapore

Russ,J.C.,2011. The Image Processing Handbook Sixth Edition, CRC Press, Boca Raton, pp.466-509

Si-Wei Chen, Sato,M, 2013. Tsunami Damage Investigation of Built-Up Areas Using Multitemporal Spaceborne Full Polarimetric SAR Images, IEEE Trans. on Geoscience and Remote Sensing, vol51, No.4,pp.1985-1997

Soille,P. and Pesaresi,M.,2002.Advances in Mathematical Morphology Applied to Geoscience and Remote Sensing, IEEE Transactions on Geoscience and Remote Sensding, vol.40,NO.9, pp.2042-2055

Soille,P.,2003. Morphological Image Analysis Principles and Applications, Springer, Berlin

Soille,P.; Martino Pesaresi,2011. Georgios K. Ouzounis Mathematical Morphology and Its Applications to Image and 
Signal Processing Proceedings of 11th International Symposium IMM2011, Springer, Berlin

Takagi,M.; Shimoda,H. (Ed.),2004. Handbook of Image Analysis Revised Edition (in Japanese), University of Tokyo Press, Tokyo, pp. 1520-1523, 864-884, 1528-1529

The Japanese Society of Rural Development Engineers, 2012. The activities report of rural development engineers dispatched to the Eastern-Japan earthquake and Tsunami disaster areas (in Japanese), pp.1-218

Watanabe,M.,Motohka,T. et al., 2012. Analysis of Urban Areas Affected by the 2011 Off the Pacific Coast of Tohoku Earthquake and Tsunami With L-Band SAR Full-Polarimetric Mode, IEEE Geoscience and Remote Sensing Letters, vol.9,No.3,pp.472-476

Yamada,Y.; Sakurai-Amano, T.; Takagi, M., 2002.Detection of flood damaged areas in the entire Chao Phraya River Basin from JERS-1/SAR Images with a help of spatial information, Proceedings of IGARSS2002, Toronto

Yamada,Y.,2001. Detection of Flood-inundated Area and Relation between the area and Micro-Geomorphology using SAR and GIS, Proceedings of IGARSS2001, Sydney

Yamada,Y., 2003.Relation between ground features and mathematical morphology using JERS-1/SAR data during flooding time in paddy areas, Proceedings of IGARSS2003, Toulouse

Yamada,Y., 2008. Morphological Analysis of Flood Inundated Regions In Paddy Areas Using ALOS/PALSAR Data and its Distribution on the Google Earth-Design of the Future Disaster Management System(FDMS) - The International Archives of the Photogrammetry, RemoteSensing and Spatial Information Sciences. Vol.XXXVII. PartB4.Beijing, pp.11171122

Yamada,Y.,2007. Flood mapping for paddy areas in Thailand and Indonesia using PALSAR data, Abstracts of The First Joint PI Symposium of ALOS Data Nodes for ALOS Science Program in Kyoto, p189, Kyoto, Japan

Yamada,Y.,2011. FLOOD EXTENT DETECTION IN PADDY AREA AND FUTURE PLAN OF DISASTER INFORMATION SHARING PLATFORM IN RURAL AREAS, Final Reports of The ALOS Research Announcement Programs 1\&2, JAXA, Japan, PI349-1-PI-349-7

Yamada,Y., 2012. MATHEMATICAL MORPHOLOGY APPROACH TO DETECT FARMLAND CONDITIONS FROM ALOS/PALSAR DATA AFTER THE 2011 OFF THE PACIFIC COAST OF TOHOKU JAPAN EARTHQUAKE AND TSUNAMI, Proceedings of IGARSS2012, Munich, pp.6118-6121

Yamada,Y.,2012. Comparison between the research result of mathematical morphology method applied to satellite SAR data and the other reported results for the detection of the 2011 off the Pacific coast of Tohoku Japan Earthquake and Tsunami affected farmlands, Proc. of SPIE Asia \& Pacific 2012, Kyoto, 2012, Vol.8524, pp.85241M1-85241M9
Yamada,Y.,2013. Mathematical Morphology Approach to the Detection of the off the Pacific coast of Tohoku Japan Tsunami reached farmland from PALSAR data, Proc. of APSAR2013, Tsukuba

Tsunami inundated areas map, 100,000:1 of off the Pacific Coast of TOHOKU JAPAN earthquake. Available online: http://www.gsi.go.jp/kikaku/kikaku60003.html (accessed on 11th August 2014)

Epicenters map of off the Pacific Coast of TOHOKU JAPAN earthquake by Japan Meteorological Agency. Available online: http://www.data.jma.go.jp/svd/eqev/data/2011_03_11_tohoku/ yoshin_teirei.png (accessed on 11th August 2014) 